\title{
An analytical chemistry experiment for charge density quantification of polyelectrolyte polysaccharides by conductometric titration
}

\begin{tabular}{|c|c|}
\hline Journal: & Journal of Chemical Education \\
\hline Manuscript ID: & ed-2011-00261w.R2 \\
\hline Manuscript Type: & Laboratory Experiment \\
\hline $\begin{array}{r}\text { Date Submitted by the } \\
\text { Author: }\end{array}$ & $\mathrm{n} / \mathrm{a}$ \\
\hline Complete List of Authors: & $\begin{array}{l}\text { Farris, Stefano; University of Milan, Food Science and Microbiology } \\
\text { Mora, Luigi; University of Milan, Food Science and Microbiology } \\
\text { Capretti, Giorgio; Italian Pulp and Paper Research Institute } \\
\text { Piergiovanni, Luciano; University of Milan, Food Science and } \\
\text { Microbiology }\end{array}$ \\
\hline Keywords: & $\begin{array}{l}\text { Upper-Division Undergraduate }<\text { Audience, Analytical Chemistry }< \\
\text { Domain, Hands-On Learning / Manipulatives < Pedagogy, } \\
\text { Carbohydrates < Topics, Conductivity < Topics, Food Science }< \\
\text { Topics, Materials Science < Topics, Titration / Volumetric Analysis }< \\
\text { Topics }\end{array}$ \\
\hline
\end{tabular}

\section{SCHOLARONE Manuscripts}




\title{
An analytical chemistry experiment for charge density quantification of
}

\section{polyelectrolyte polysaccharides by conductometric titration}

\author{
Stefano Farris ${ }^{\mathrm{a},{ }^{*},}$, Luigi Mora ${ }^{\mathrm{a}}$,Giorgio Capretti ${ }^{\mathrm{b}}$, Luciano Piergiovanni ${ }^{\mathrm{a}}$ \\ ${ }^{a}$ DiSTAM, Department of Food Science and Microbiology - University of Milan, Via Celoria 2 - 20133 Milan, Italy \\ ${ }^{b}$ SSCCP, Italian Pulp and Paper Research Institute, Piazza L. da Vinci 16-20133 Milan, Italy
}

\begin{abstract}
We present an easy analytical method for determination of the charge density of polyelectrolytes, including polysaccharides and other biopolymers. The basic principles of conductometric titration, which is used in the pulp and paper industry, as well as in colloid and interface science, were adapted to quantify the charge densities of a negatively charged polysaccharide (pectin) and a positively charged biopolymer (chitosan): two biomacromolecules commonly used in food and biomaterials applications. We demonstrate that this novel conductometric titration method can be easily applied in most analytical chemistry teaching laboratories, due to its ease-of-use, safety, and educational benefits. This analytical technique can be used in a wide-range of laboratory activities, and has extensive research applications in areas of chemistry involving charged biopolymers, such as food science, materials science and physical chemistry.
\end{abstract}

KEYWORDS: (Upper-Division Undergraduate). (Analytical chemistry). (Hands-On Learning / Manipulatives). (Carbohydrates / Conductivity / Food Science / Materials Science/ Titration).

\footnotetext{
*Corresponding author. Tel.: +39 0250316654; Fax: +39 0250316672

Email address: stefano.farris@unimi.it (S. Farris) 
Titration is a commonly used analytical technique in many research and classroom laboratory activities, and is defined as the addition of a solution with known concentration (the titrant) to a second solution with an unknown concentration (the analyte), with the goal of determining the concentration of the latter. Titration is complete when a specific endpoint is reached, which is normally determined visually by an indicator. There are several methods for endpoint determination, which normally require dedicated equipment: pH indicators (e.g., phenolphthalein), redox indicators, $\mathrm{pH}$ meters, conductometers, potentiometers, $\zeta$-potential, isothermal calorimeters, spectrophotometers, and amperometric instruments.

This article focuses on conductometric titration, a titration technique based on measuring conductance changes during stepwise addition of a titrant to an analyte. The conductivity of a solution depends on several factors, including: solute concentration, the degree of solute dissociation, the valence of the ion(s) present in the solution, temperature, and the mobility of the ions in the solution. Conductometric titration is a very versatile technique, with a wide range of applications. It is a well-established analytical method for simple acid-base systems (1-2); and has recently been applied to analyze biological molecules for various purposes (3-5). In addition, conductometric measurements are routinely conducted in the pulp and paper industry: to enhance the mechanical performance of paper by absorption of additives onto the fiber surface; for deposition of colloidal materials, such as small cellulose fragments and filler particles; or when stoichiometric neutralization of anionic trash is required (6-7). In fact, the potential usefulness of conductometric titration as a routine laboratory technique was proposed in textbooks over twenty years ago (8). Moreover, the basic principles behind related conductometric titration apparatus have been published in this Journal (9-14). 
In light of the rapidly increasing interest in the use of biomacromolecules for a broad spectrum of practical applications, in the present work, we describe an 'easy-to-use' conductometric titration method to quantify the charge density of biomacromolecule polyelectrolytes. The charge density, defined as the amount of electric charge per mass unit, provides a quantitative measure of the charged groups along the molecular backbone. These groups may be either positively charged or negatively charged. There are several methods for the determination of the charge density, among which electrophoretic and light scattering techniques, colloidal titation and $\mathrm{pH}$ titration are the most widely exploited. In this paper, we illustrate pedagogically the advantages of conductometric titration for determination of the charge density of polyelectrolyte biopolymers, such as chitosan and pectin; model cationic and anionic model polyelectrolytes, respectively. The educational goal of this work is to introduce young students to the fascinating world of biomacromolecules, and to teach students how to manipulate and investigate their versatile nature using a simple analytical technique. These presented student experiments have been successfully used for teaching purposes, in particular within lab activities of undergraduate students of the Food Science program. The entire activity includes three different parts: i) set up of the experiment ( 30 minutes $)$, ii) carrying out the conductometric titration experiments ( 150 minutes $)$ and iii) data analysis ( 30 minutes).

\section{Experimental procedures}

1) Materials: All required raw materials can be readily purchased from chemicals suppliers: 0.1 $\mathrm{N}$ hydrochloric acid $(\mathrm{HCl}), 0.1 \mathrm{~N}$ sodium hydroxide $(\mathrm{NaOH})$, high-purity poly-galacturonic acid and low-methoxyl pectin from citrus with a degree of esterification $(\mathrm{DE})=28.5 \%$, were purchased from Sigma-Aldrich (Milan, Italy). Medium molecular weight shellfish chitosan was 
kindly provided by Giusto Faravelli Spa (Milan, Italy). The degree of acetylation, DA (\%), of the chitosan was approximately $16.13 \%$.

2) Sample Preparation: Pectin, an anionic polyelectrolyte, and chitosan, a cationic polyelectrolyte, must be dispersed in water before use. A highly dilute dispersion (e.g. 0.1 wt.\%) can be prepared in approximately 30 minutes (see supporting materials).

3) Conductometric Titration Instrument set-up: To simultaneously monitor the $\mathrm{pH}$ and conductivity of the prepared dispersion, the $\mathrm{pH}$ meter and conductometer must be carefully fixed close to the beaker containing the water dispersion (the analyte). A magnetic stirrer must be used to continuously mix the water dispersion throughout the experiment. Because both $\mathrm{pH}$ and conductivity are strongly influenced by temperature, a temperature-controlling device should be used to ensure that this parameter is constant during analysis. In addition, because the titrant should be dispensed precisely, the use of an automatic microburette is highly recommended. However, for the purposes of student laboratory exercise a manual burette is sufficient. A typical instrument set-up is illustrated in Figure 1. Set-up will normally require approximately 30 minutes.

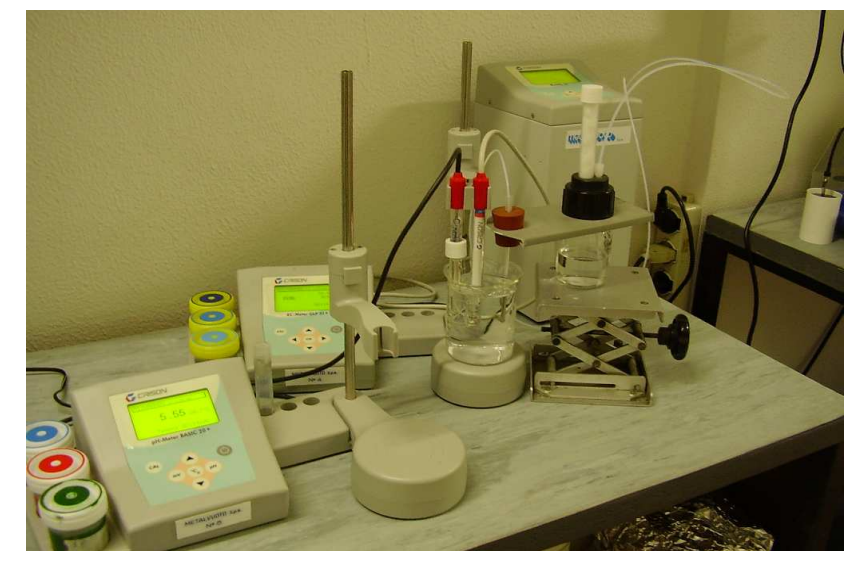

Figure 1. Illustration of the equipment required for conductometric titration. 


\section{4) Analyses:}

Conductometric Titration of Pectin: A pectin aqueous dispersion (0.1 wt $\%$ ) was first treated with an excess $(15 \mathrm{~mL})$ of $0.1 \mathrm{~N}$ hydrochloric acid $(\mathrm{HCl})$, in order to completely neutralize the negative charge distributed along the pectin backbone, due to unprotonated carboxylic groups. Conductometric titration was performed by adding $0.1 \mathrm{~N}$ sodium hydroxide $(\mathrm{NaOH})$ under gentle stirring (100 rpm). Ionic conductivity was evaluated after sequential injections of $\mathrm{NaOH}$, in 3 different stages: 1) initially, $0.5 \mathrm{~mL}$ drops were dispensed at a flow rate of $0.40 \mu \mathrm{L} \mathrm{s}{ }^{-1}$; as the conductance decreased (approaching the first equivalence point) the dispensed volume was reduced to $0.1 \mathrm{~mL}$ at a flow rate of $0.15 \mu \mathrm{L} \mathrm{s}^{-1}$; beyond the 'constant-conductivity' region, initial conditions were used, $0.5 \mathrm{~mL}$ drops were dispensed at a flow rate of $0.40 \mu \mathrm{L} \mathrm{s}^{-1}$. The titrant was added approximately every 60 seconds, to allow sufficient time for equilibrium to be reached between readings. $\mathrm{pH}$ was continuously measured simultaneously.

Conductometric Titration of Chitosan: Conductometric titration of chitosan aqueous dispersion $(0.1 \mathrm{wt}-\%)$ was performed without any prior neutralization step. Hydrochloric acid $(0.1 \mathrm{~N} \mathrm{HCl})$ was added approximately every 2 minutes in two different stages: 1) initially, $0.1 \mathrm{~mL}$ drops were dispensed at a flow rate of $0.15 \mu \mathrm{L} \mathrm{s}^{-1}$; as the conductance increased (after the breakpoint) the dispensed volume was increased to $0.5 \mathrm{~mL}$, with a flow rate of $0.40 \mu \mathrm{L} \mathrm{s}^{-1}$. Ionic conductivity was evaluated after each addition of titrant, and $\mathrm{pH}$ was continuously measured.

Conductometric titration of both biopolymers requires approximately 2 hours. 
5) Charge density determination: Plotting the above measured ionic conductivity versus total titrant concentration enables determination of the charge density (as equivalent charge) of both polyelectrolytes. From the intersection points of the linear segments of the ionic conductivity plot before and after the equivalent points (or breakpoints), it is possible to graphically determine the amount $(\mathrm{mL})$ of titrant required to fully deprotonate all carboxylic groups on pectin, or fully protonate all amino groups on chitosan. By multiplying this value by its concentration (normality), and referring to the initial polyelectrolyte mass, the charge density of the polymer (mmol $\mathrm{g}^{-1}$ ) can be easily calculated. A detailed example is reported in the Supporting Information material. This step normally requires 30 minutes.

\section{Results and Discussion}

Pectin

Figure 2 shows the typical evolution of ionic conductivity $(\chi)$ and $\mathrm{pH}$ versus the volume of titrant for dilute aqueous pectin dispersions.

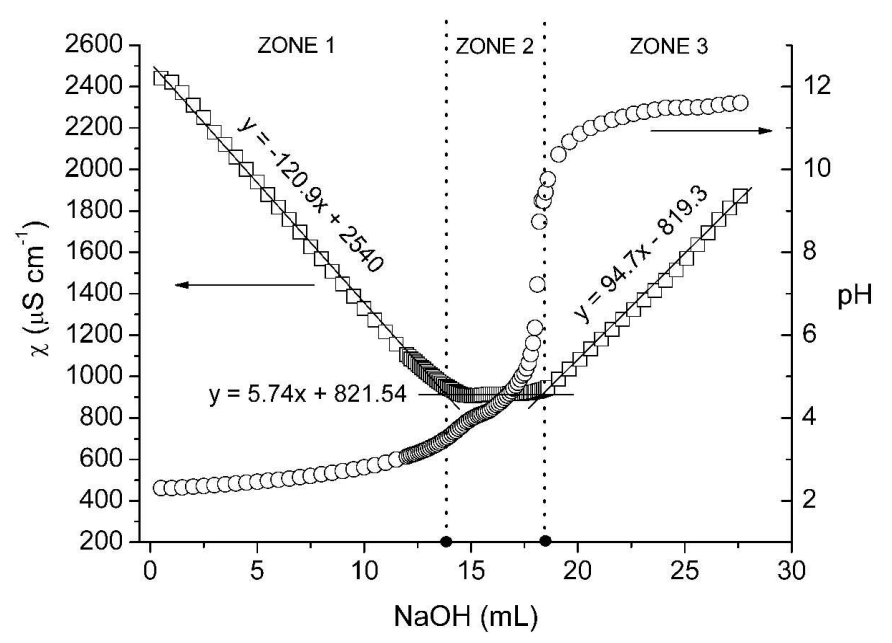

Figure 2. Mean conductometric and potentiometric titration curves for pectin $(\mathrm{DE}=28.5 \%)$. 
Both curves clearly display 3 distinct zones, corresponding to 3 distinguishable physicochemical phenomena. In zone 1, the first descending part of the conductometric curve is due to neutralization of dissociated hydrogen ions from the previously added $\mathrm{HCl}$ (Figure 3a), as shown by the following reaction:

$$
\mathrm{NaOH}+\mathrm{H}^{+}+\mathrm{Cl}^{-} \leftrightarrows \mathrm{H}_{2} \mathrm{O}+\mathrm{Na}^{+}+\mathrm{Cl}^{-}
$$

Because the equivalent ionic conductance of $\mathrm{H}^{+}\left(350 \mathrm{~S} \mathrm{~cm}^{2} \mathrm{~mol}^{-1}\right)$ is approximately 7-times greater than the mobility of $\mathrm{Na}^{+}\left(50.9 \mathrm{~S} \mathrm{~cm}^{2} \mathrm{~mol}^{-1}\right)(15,16)$, the net effect is a decrease in conductivity. At the same time, the $\mathrm{pH}$ increases moderately as the concentration of hydrogen ions decreases. As the first equivalence point is approached, neutralization of the excess $\mathrm{H}^{+}$is complete and carboxylic acid groups began to dissociate (zone 2). In this zone, no changes in conductance values occurs, because of the neutralization of dissociated hydrogen ions from the pectic acid backbone by hydroxide ions $\left(\mathrm{OH}^{-}\right)$, which arise from the addition of titrant (Figure $3 b)$ according to the following reaction scheme:

$$
-\mathrm{COOH}+\mathrm{Na}^{+}+\mathrm{OH}^{-} \leftrightarrows-\mathrm{COO}^{-}+\mathrm{Na}^{+}+\mathrm{H}_{2} \mathrm{O}
$$




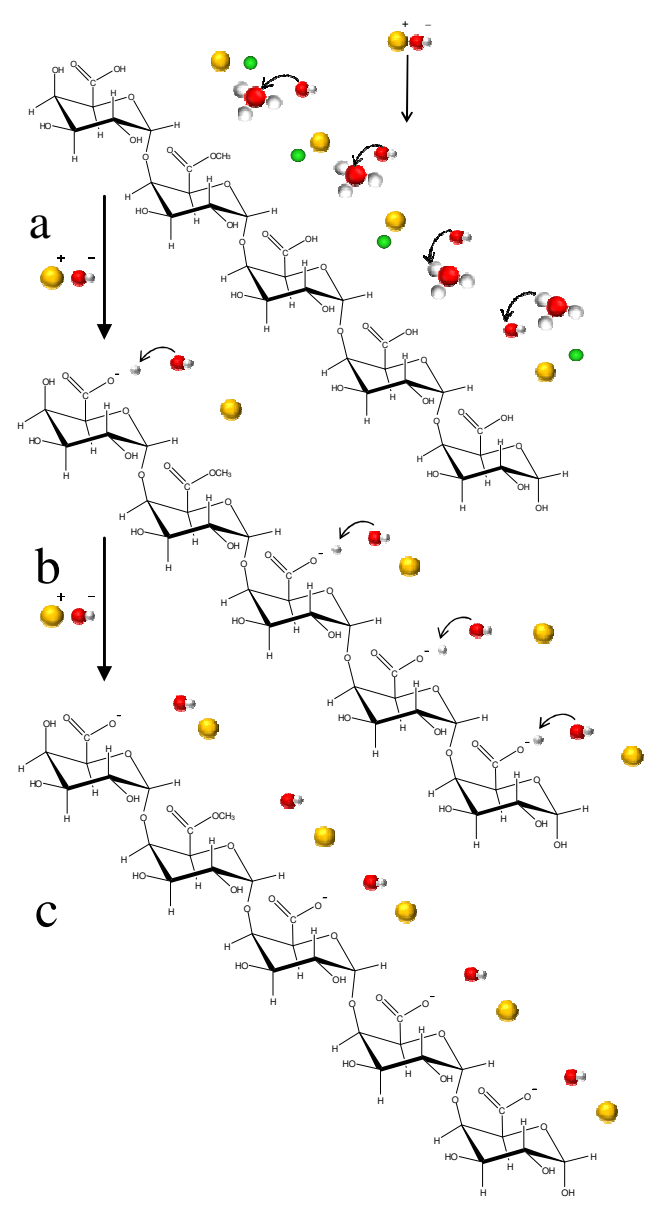

Figure 3. Schematic representation of chemical changes induced by $\mathrm{NaOH}$ titration of the pectin backbone: a) neutralization of hydrogen ions (excess $\mathrm{HCl}$ ) by $\mathrm{NaOH}$; b) early dissociation of carboxylic groups mediated by hydroxide ions; c) from pectic acid to pectate, dissociation of all carboxylic groups.

Simultaneously, the $\mathrm{pH}$ of the pectic acid dispersion progressively increases as deprotonation of the carboxylic groups proceeds, due to increasing amounts of free $\mathrm{OH}^{-}$ions in the dispersion. Zone 3 begins beyond the second equivalence point. Because carboxylic groups have already been titrated, the conductance increases in proportion to the $\mathrm{OH}^{-}$excess in the dispersion, arising from dissociation of the $\mathrm{NaOH}$ dispensed (the hydroxyl equivalent ionic conductivity is $\sim 192 \mathrm{~S}$ $\mathrm{cm}^{2} \mathrm{~mol}^{-1}$ ) (Figure 3c). At this point, addition of even small amounts of titrant will yield a 
dramatic increase in $\mathrm{pH}$, until $\mathrm{NaOH}$ dissociation becomes progressively hindered by higher concentrations.

According to the graphical method described in the previous section, the final anionic charge density of pectin is $2.471 \pm 0.123 \mathrm{mmol} \mathrm{g}^{-1}$, or approximately $0.492 \mathrm{mmol} / 0.2 \mathrm{~g}$ of pectin.

\section{Chitosan}

The degree of acetylation, DA (\%), of the chitosan used in this work was approximately $16.13 \%$, corresponding to a degree of deacetylation (DD) of $\sim 83.87 \%$. A typical evolution of ionic conductivity $(\chi)$ and $\mathrm{pH}$ versus volume of titrant for dilute aqueous chitosan dispersions is shown in Figure 4.

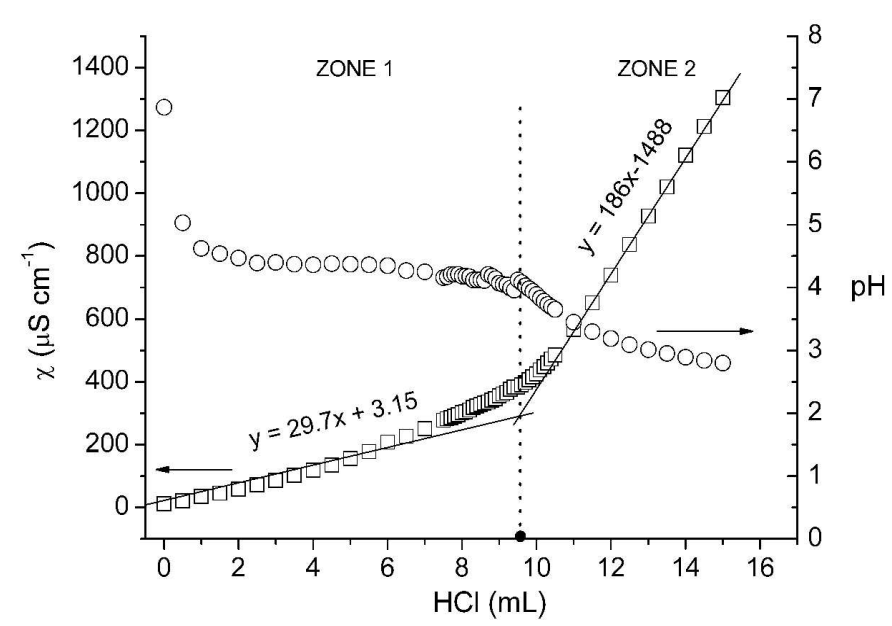

Figure 4. Mean conductometric and potentiometric titration curves for chitosan (DD = 83.87\%).

Both curves clearly display 2 distinct zones. Initially, the $\mathrm{pH}$ of the chitosan dispersion is above the $\mathrm{pK}_{\mathrm{a}}$ of chitosan ( 6.5), with the absence of any predominant charge along the polysaccharide molecule; thus, all amino groups $\left(-\mathrm{NH}_{2}\right)$ are in their unprotonated form. The absence of positive charge greatly influences the physical properties of chitosan dispersions, by affecting its solubility in water. In support of this, chitosan dispersions prepared in this work initially appeared very cloudy (i.e., high turbidity), due to the presence of insoluble particles of 
solute dispersed in the solvent. The lack of solubility of native chitosan in water has been ascribed to its inherent physical structure. Specifically, its $\beta$-1,4-configuration results in a rigid and unbranched structure, whereas the abundance of hydroxyl groups (one primary hydroxyl at C-6 and one secondary hydroxyl at C-3) and a highly reactive amino group (at C-2) explain the tendency for intra- and inter-molecular hydrogen bond formation (Figure 5a). Increasing amounts of titrant $(\mathrm{HCl})$ gradually lead to an increase in the solubility of chitosan, with a simultaneous increase in the transparency of the chitosan dispersion. This is due to protonation of amino groups $\left(-\mathrm{NH}_{3}{ }^{+}\right)$, which promotes unfolding of the chitosan molecules by electrostatic repulsion (Figure 5b). Simultaneously (with the exception of an initial decrease in $\mathrm{pH}$, presumably because of system stabilization), the $\mathrm{pH}$ values of the chitosan dispersion remain steady up to the equivalence point, due to continuous protonation of $-\mathrm{NH}_{2}$ groups; while conductivity values increase slightly, because of the release of free chloride anions $\left(\mathrm{Cl}^{-}\right)$. The end of the first zone is assumed to correspond to the total protonation of amino groups, and maximum transparency of the chitosan dispersion is attained at this point (no chitosan particles can be seen by visual inspection). Further addition of hydrochloric acid prompts a steep increase in conductivity, due to the larger conductivity of hydrogen cations compared to chloride anions (Figure 5c). 
a
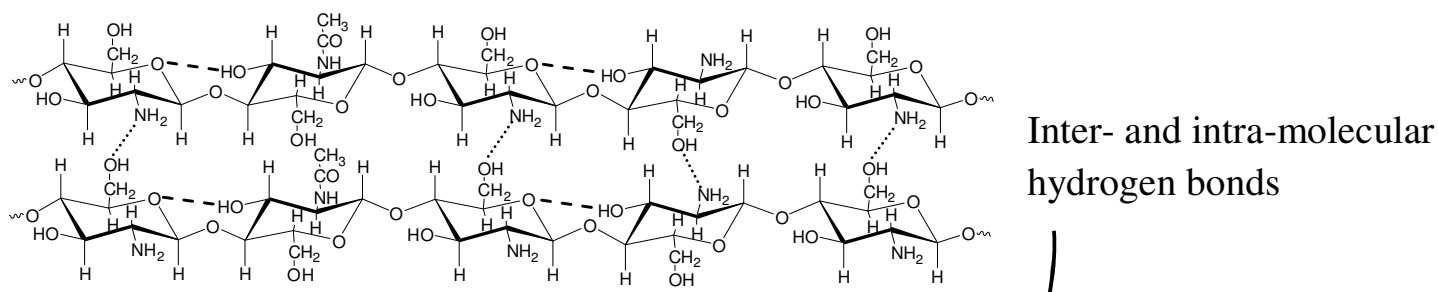
hydrogen bonds

b

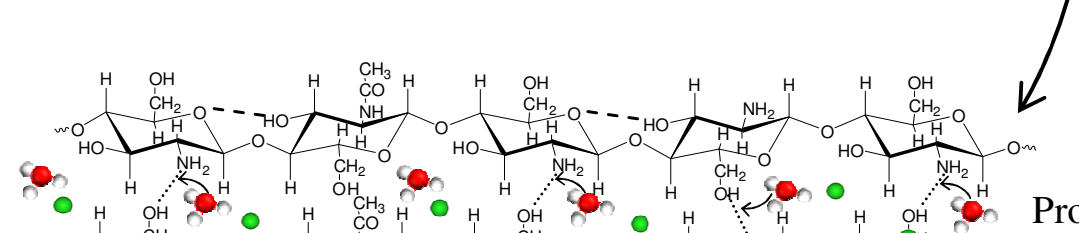

Protonation of amino groups
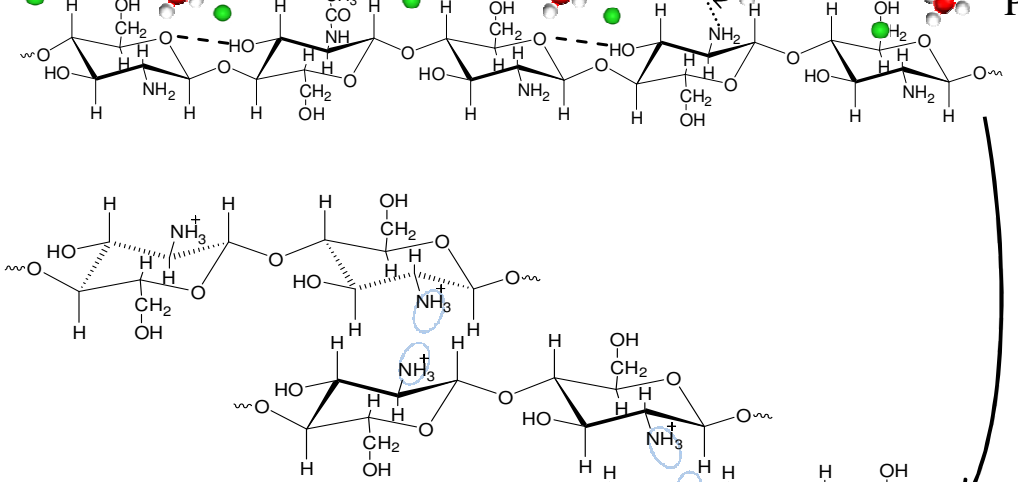

c

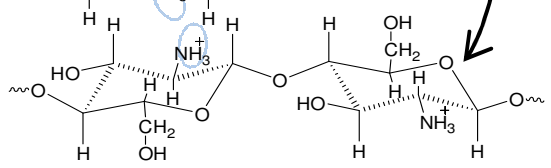

Electrostatic repulsion

Figure 5. Schematic representation of chemical changes induced by $\mathrm{HCl}$ titration of the chitosan backbone: a) undissolved chitosan with unprotonated amino groups. Dashed lines indicate O3- -O5 intra-molecular hydrogen bonds. Dotted lines indicate inter-molecular N2- - -O6 hydrogen bonds between two adjacent polymer chains; b) partial protonation of amino groups is promoted by the addition of $\mathrm{HCl}$ (figure shows the hydronium ion $\mathrm{H}_{3} \mathrm{O}^{+}$and the chloride ion $\mathrm{Cl}^{-}$); c) full protonation of amino groups leads to complete solubility of chitosan because of increased polarity and electrostatic repulsion.

This is also consistent with slope values from the two distinct linear segments of the conductivity curve. The slope of the first linear segment of the conductivity curve is 
approximately 6-fold greater than the slope of the second linear segment $\left(\sim 30 \mu \mathrm{S} \mathrm{mL} \mathrm{cm}{ }^{-1} v s\right.$. $\left.\sim 185 \mu \mathrm{S} \mathrm{mL} \mathrm{cm}{ }^{-1}\right)$, in agreement with the smaller equivalent conductivity of $\mathrm{Cl}^{-}$ions $\left(75.5 \mathrm{~S} \mathrm{~cm}^{2}\right.$ $\mathrm{mol}^{-1}$ ) compared to the $\mathrm{H}^{+}$ions. Accordingly, $\mathrm{pH}$ values start to decrease from this point on, and throughout the second zone, due to increasing amounts of free $\mathrm{H}^{+}$ions in the medium. Based on these observations, we assume the equivalence point is located at the intersection of the two linear segments of the curve, from which the corresponding amount of titrant used can be extrapolated. The calculated anionic charge of chitosan was $4.660 \pm 0.056 \mathrm{mmol} \mathrm{g}^{-1}$, or 0.932 mmol/0.2 g sample.

\section{Conclusions}

The results outlined above demonstrate that this conductometric technique is a valid method for quantifying the charge density of dilute solutions of polyelectrolyte polymers, such as polysaccharides. This tool could be especially relevant when assembly of biopolymers governed by electrostatic forces is required. In addition, because this technique is relatively rapid, safe, and easy-to-use, it can be successfully adapted for teaching laboratories for undergraduate student courses.

\section{HAZARDS}

The conductometer, $\mathrm{pH}$ meter and data logger are safe to use; however, high voltage power supplies must be used with caution. Concentrated sodium hydroxide solution is caustic; although high temperatures may result upon mixing sodium hydroxide with water, this was not observed during the stepwise sodium hydroxide titration described above. Both hydrochloric acid and sodium hydroxide solutions should only be handled (filling, closing, and shaking) while wearing 
a protective lab coat, gloves, and safety glasses. The pectin and chitosan used in these experiments are safe, and are used as food ingredients. However, very low mesh powders may be irritating to the respiratory tract. Therefore, a protective mask is recommended during handling.

\section{Literature Cited}

(1) Smith, K.C.; Edionwe, E.; Michel, B. J. Chem. Educ. 2010, 87, 1217-1221.

(2) Nyasulu, F.; Stevanov, K.; Barlag, R. J. Chem. Educ. 2010, 87, 1364-1366.

(3) Li, Q.; Song, B.; Yang, Z.; Fan, H. Carbohyd. Polym. 2006, 63, 272-282.

(4) Weinbreck, F.; Nieuwenhuijse, H.; Robijn, G. W.; de Kruif, C. G. J. Agric. Food Chem. 2004, 52, 3550-3555.

(5) Mascheroni, E.; Capretti, G.; Marengo, M.; Iametti, S.; Mora, L.; Piergiovanni, L.; Bonomi, F. Packag. Technol. Sci. 2010, 23, 47-57.

(6) Fardim, P.; Holmbom, B.; Ivaska, A.; Karhu, J. Nordic Pulp Pap. Res. J. 2002, 17, 346351.

(7) Laine, J.; Stenius, P. Pap. Puu-Pap. Tim. 1997, 79, 257-266.

(8) Vogel, A.I. Textbook of quantitative chemical analysis, 5th edition; Longman Scientific \& Technical: Harlow, England, 1989; pp 519-528.

(9) Katz, D.A.; Willis, C. J. Chem. Educ. 1994, 71, 330-332.

(10) Zawacky, S.K.S. J. Chem. Educ. 1995, 72, 728-729.

(11) Da Rocha, R.T.; Gutz, I.G.R.; do Lago, C.L. J. Chem. Educ. 1997, 74, 572-574. 
(12) Haworth, D.T.; Bartelt, M.R.; Kenney, M.J.; Howald, R. J. Chem. Educ. 1999, 76, 625627.

(13) Ganong, B.R. J. Chem. Educ., 2000, 77, 1606-1608.

(14) Papadopoulos, N.; Limniou, M. J. Chem. Educ. 2001, 78, 245-246.

(15) Rouessac, F.; Rouessac, A. Chemical analysis: modern instrumentation methods and techniques, 2nd edition; Wiley: Hoboken, NY, 2007; p 101.

(16) Ötleş, S. Handbook of food analysis instruments; CRC Press: Boca Raton, FL, 2008; p 173.

Supporting Information Available: Teacher and student guide to conductometric titrations. Full details of the operative conditions. This supporting material is available via the Internet at http://pubs.acs.org. 